\title{
Attenuated self-serving bias in people with internet gaming disorder is related to altered neural activity in subcortical-cortical midline structures
}

\author{
Yifan Wang ${ }^{1}$, Li Zheng ${ }^{1}$, Chenggong Wang ${ }^{1 *}$ (D) and Xiuyan Guo ${ }^{1,2,3}$
}

\begin{abstract}
Background: To protect and maintain the positivity of self-concept, normal people usually show a self-serving bias (internal attribution of positive events and external attribution of negative events) by the motives of selfenhancement and self-protection. Additionally, self-serving assessments predominantly activate the subcorticalcortical midline structures (CMS) in healthy individuals. However, little is known about self-serving bias and its underlying neural correlates among individuals with Internet gaming disorder (IGD).

Methods: Twenty-four participants with IGD and 25 recreational Internet gaming users (RGUs) were scanned while attributing the causes of positive/negative self- and other-related events that could occur in both the game-world and real-world contexts. Region-of-interest (within CMS regions) and parametric analysis were performed to investigate the neural correlates of self-serving bias in IGD.

Results: Behaviorally, the IGD participants attributed more negative and fewer positive events to themselves than RGU participants in both contexts. Neurally, during the attributions of negative events, the IGD participants exhibited increased ventromedial prefrontal cortex (VmPFC) activation in both contexts compared with RGU participants. Higher vmPFC activation was associated with weaker self-protective motivation in the IGD group. Meanwhile, during the attributions of positive events, the IGD participants exhibited decreased precuneus/posterior cingulate cortex activation in the real world compared with RGU participants. Parametric analysis showed a reduced positive correlation between precuneus activation and self-attribution ratings of positive events in the real world in the IGD group relative to the RGU group.

Conclusion: These results suggest that individuals with IGD show an attenuated self-serving bias and altered brain activity within CMS regions involved in self-attribution, providing evidence for the negative self-concept and weakened abilities in both self-enhancement and self-protection in IGD.
\end{abstract}

Keywords: Internet gaming disorder, Self-serving bias, vmPFC, Precuneus

\footnotetext{
* Correspondence: chenggong891020@163.com

'School of Psychology and Cognitive Science, East China Normal University, No. 3663, North Zhongshan Road, Shanghai 200062, China

Full list of author information is available at the end of the article
}

(C) The Author(s). 2020, corrected publication 2020. Open Access This article is licensed under a Creative Commons Attribution 4.0 International License, which permits use, sharing, adaptation, distribution and reproduction in any medium or format, as long as you give appropriate credit to the original author(s) and the source, provide a link to the Creative Commons licence, and indicate if changes were made. The images or other third party material in this article are included in the article's Creative Commons licence, unless indicated otherwise in a credit line to the material. If material is not included in the article's Creative Commons licence and your intended use is not permitted by statutory regulation or exceeds the permitted use, you will need to obtain permission directly from the copyright holder. To view a copy of this licence, visit http://creativecommons.org/ licenses/by/4.0/. The Creative Commons Public Domain Dedication waiver (http://creativecommons.org/publicdomain/zero/1. 0/) applies to the data made available in this article, unless otherwise stated in a credit line to the data. 


\section{Background}

With the rapid development of network and information technology, the Internet has become a ubiquitous tool for the convenience of human life. However, the negative impacts of excessive Internet use have gradually been brought into public view. In particular, some individuals play online games excessively and persistently without considering the severe consequences, such as disrupted relationships, social deficits and poor academic/work performance $[1,2]$. This manner of overusing online games is widely known as Internet gaming disorder (IGD), which has several clinical features such as loss of control, poor time management and craving [3-5]. IGD is associated with symptoms of salience, relapse and withdrawal similar to those observed with problematic gambling and drug addictions and is also associated with psychiatric disorders in young people including depression, anxiety, attention deficit and hyperactivity disorder and alcohol misuse [68]. IGD, as a specific type of behavioral addiction, has been listed in the Section III of Diagnostic and Statistical Manual of Mental Disorders Fifth Edition (DSM-V) in 2013 and has been recently included in the 11th Revision of the International Classification of Diseases (ICD-11) [9, 10]. In the past decade, extensive empirical studies have focused on the complex set of cognitive processes in IGD and converged to the same findings that individuals with IGD exhibit impaired decision-making, poor executive control abilities and enhanced reward sensitivity [11-13].

Importantly, these cognitive processes cannot be fully separated from the self which is an essential and core prerequisite for individuals to form their own perspectives, characteristics and behaviors [14]. Normal people usually have a motive to seek an accurate, stable and positive selfconcept [15]. To preserve positive self-view and deflect negative feedbacks, individuals generally tend to attribute positive outcomes (e.g., success) to internal causes and negative outcomes (e.g., failure) to external causes, which is referred to as self-serving bias [16]. This type of cognitive bias has been extensively investigated in laboratory-based studies and is suggested to be engaged by two motivational components - self-protection and self-enhancement [17, 18]. When encountering undesirable and potentially damaging things (e.g., failure), one will diminish the meaning and implications of the things to maintain positive selfview. Such a belief is thought to be self-protection that defends against negative self-concept. When achieving desirable and potentially enhancing things (e.g., success), one will exaggerate its own ability and talent to enhance the self. Such a belief is thought to be selfenhancement that helps to elevate positive self-concept. Although the self-serving bias may not accurately reflect reality, it is seriously deemed an adaptive function of preserving and enhancing self-esteem and positive self-concept $[15,19,20]$.
However, it remains unclear how the self-serving bias is manifest in IGD. Notably, research has recently reported that individuals with IGD evaluated both actual self and ideal self more negatively, suggesting a distorted selfconcept in IGD [21]. Furthermore, a growing body of surveys has reported that IGD is associated with low selfesteem and high depression [22, 23]. Research has demonstrated that individuals who reported a low level of selfesteem or who were moderately depressed displayed diminished self-serving bias or non self-serving bias [24, 25]. These findings may imply that there has been an attenuated self-serving bias in IGD. In the present study, we utilized a causal attribution task (attributions of positive/ negative self- and other-related events) to address this issue [26]. Using this task, we could detect the attribution differences between self- and other-related (considered as the baseline) interpersonal events to identify the characteristics of self-serving bias in individuals with IGD. More critically, we also differentiated the attributions of negative and positive interpersonal events to accurately probe that the reduction of self-serving bias occurred in selfprotection bias or self-enhancement bias or both.

Neuroimaging studies have identified that the processing of self-relevant stimuli elicits brain activity in the midline of the human cerebral cortex (cortical midline structures, CMS), mainly including the ventromedial PFC (vmPFC), dorsomedial PFC (dmPFC) and precuneus/posterior cingulate cortex (precuneus ${ }_{\mathrm{pcc}}$ ) regions $[27,28]$. For example, individuals show CMS activation when passively viewing personal semantic facts such as one's own first name [29]. Furthermore, it is also proved that self-serving assessments are associated with the engagement of the regions within CMS [26, 30-32]. Specifically, Beer \& Hughes found that the recruitment of vmPFC could predict the extent to which individuals viewed themselves as more desirable than other people [32]. The vmPFC also contributes to prompt self-protective behaviors against social negative feedbacks from partners [33]. A study conducted by Cabanis et al. found that the precuneus $\mathrm{scc}_{\mathrm{pcc}}$ is engaged in the processes of internal attributions for negative or positive social situations [34]. In particular, numerous studies have identified that IGD is associated with functional or structural neural alterations in the

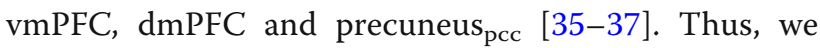
mainly focused on the neural activities of these CMS regions related to self-serving bias during the attributions of interpersonal events in IGD.

In the present study, the participants were scanned while attributing the causes of positive/negative self- and other-related events. Except for exploring the self-serving bias in the real world, we also explored this cognitive process in the Internet game world, considering that the individuals with IGD preferably use games to escape discomfort and are immersed in a virtual environment where 
they interact with other players. The participants' real names and game names were used to represent themselves in the real world and game world, respectively. Similar to having game experience and spending a certain amount of time on games but not having IGD, recreational Internet gaming users (RGUs) are suitable to serve as the comparison group [38-40]. Thus, IGD and RGU participants were recruited in this study and completed a causal attribution task including game-world and realworld contexts during an fMRI scan. We compared the characteristics of self-serving bias from two aspects of selfprotection and self-enhancement and the underlying neural correlates between the IGD and RGU groups under these two contexts. Based on previous research mentioned in the preceding texts, we hypothesized that compared with RGU group, IGD group (1) would generally exhibit an attenuated self-serving bias (diminished self-protection or self-enhancement or both) at the behavioral level and (2) would show altered brain activity within CMS at the neural level. We also examined the correlations between neural activity and behavioral performances in these two groups.

\section{Methods}

\section{Participants}

Fifty-five participants (26 IGD and 29 RGUs) were recruited from college campuses through WeChat and advertisements. All the participants were right-handed college students and free of any substance dependences (e.g., cocaine and alcohol) and other behavioral addictions (e.g., problematic gambling). None of them reported historical or current psychiatric diseases (e.g., depression and anxiety), brain surgery/brain injury, and neurological disorders. Additionally, six participants were excluded due to choosing the same option in more than $90 \%$ of the trials (1 RGU) or larger head motion than $3 \mathrm{~mm} /$ degree in any direction (2 IGD and 3 RGUs) during fMRI scanning. Thus, 24 IGD participants (10 women and 14 men) and 25 matched RGU participants (6 women and 19 men) were included in the final data analyses. The demographic characteristics of the IGD and RGU groups are listed in Table 1.
The participants were selected based on the types of online games they played, Internet Addiction Test (IAT) developed by Young [41], nine-item criteria proposed by the DSM-V committee [2] and amounts of time for game playing. The type of multi-player competitive game was chosen (e.g., Stimulate the battlefield, Arena of Valor); in these game environments, the player could interact with other players via the online environment. The Young's IAT comprised of 20 (5-point) Likert-type items; the total score ranging from 20 to 100 reflects the severity of IGD. Both the IAT and DSM-V criteria were exactly translated into Chinese for the sake of Chinese participants. According to previous studies, the participants were classified as IGD according to the following criteria: (1) scored 55 or higher on Young's IAT; (2) met at least five DSM-V criteria; (3) played online games for at least $2 \mathrm{~h}$ a day and had at least 2 years of game experience $[38,39]$. For the RGU participants, they scored lower than 50 on the Young's IAT and met less than five DSM-V criteria. To control the effect of the patterns of gaming, the RGU group also satisfied the third criteria mentioned above and had almost the same playtime as the IGD group. However, the RGU group reported that they prioritized their academic work/examination over games without developing psychological dependence.

The two groups showed no significant difference in age, education year, sex ratio or time spent on Internet games (PS $>0.05$; Table 1). However, the IGD group reported higher scores on Young's IAT and more items of DSM criteria than the RGU group $\left(P_{S}<0.001\right.$, Table 1$)$. All the participants were paid after completing the whole experiment.

\section{Task and procedure Task and materials}

In the present study, we adopted a modified version of a causal attribution task [26]. In the original task, the participants were presented with a series of sentences describing self-relevant (e.g., I like John, John hits me) and otherrelevant (e.g., Lily likes David, Lily hits David) interpersonal events. Each sentence comprised a subject, a verb and an object. In self-related events (happening between

Table 1 Demographic and clinical characteristics of IGD $(n=24)$ and RGU $(n=25)$ groups

\begin{tabular}{|c|c|c|c|c|}
\hline & IGD $(M \pm S D)$ & $\operatorname{RGU}(M \pm S D)$ & $t$ value & $p$ value \\
\hline Age (years) & $20.17 \pm 1.97$ & $21.00 \pm 2.52$ & -1.29 & 0.20 \\
\hline Gender(F/M) & $10 / 14$ & $6 / 19$ & $\mathrm{n} / \mathrm{a}$ & 0.19 \\
\hline Year of education & $16.54 \pm 1.38$ & $17.12 \pm 2.00$ & 1.17 & 0.25 \\
\hline Time spent on games per week (hour) & $17.29 \pm 4.47$ & $16.00 \pm 3.67$ & 1.11 & 0.27 \\
\hline IAT & $63.25 \pm 6.17$ & $41.08 \pm 7.49$ & 11.28 & $<0.001$ \\
\hline DSM & $5.63 \pm 0.88$ & $2.80 \pm 1.44$ & 8.24 & $<0.001$ \\
\hline Self-Esteem & $27.83 \pm 4.28$ & $30.28 \pm 3.61$ & -2.17 & 0.035 \\
\hline BDI & $11.08 \pm 8.12$ & $6.76 \pm 5.33$ & 2.21 & 0.032 \\
\hline
\end{tabular}


the self and another person), the participants were involved in the situation; in other-related events (happening between two other persons), the participants were observers, and the other persons were not known to them (strangers). The participants were instructed to imagine the event happening, and then evaluate using a four-point Likert scale that asked how likely was it that they attributed the cause of an event to themselves or others $(1=$ very unlikely, $2=$ moderately unlikely, 3 = moderately likely, $4=$ very likely).

To detect the self-serving bias in both the real-world and game-world contexts, we reconstructed interpersonal events that could occur not only in the real world but also in the game world. We screened 40 Chinese verbs to construct one-sentence interpersonal events. First, a series of positive and negative two-character verbs were collected and rated by 30 college students on a 9-point Likert scale for arousal, familiarity and valence. Next, ten game players (not participating in formal experiment) were invited to choose the verbs depicting events that could occur in both real world and game world. Finally, 40 verbs (20 positively valenced and 20 negatively valenced) were selected by all the players and determined to construct interpersonal events. These two types of verbs differed in valence $(t=$ 26.17, $p<0.001$ ) but not in arousal or familiarity ( $p s>0.05$ ).

Additionally, each participant's real name and game name were collected and used to describe self-related events that could occur in the real-world and game-world contexts, respectively. Similarly, the others' real names (randomly generated using Chinese common first names and last names) and game names (randomly collected via Internet search engines) were used to describe other-related events that could occur in real-world and game-world contexts, respectively.

Each verb was used four times to construct four different categories of interpersonal events according to the combinations of Target (self, other) and Context (real world, game world). Thus, 160 interpersonal events were obtained - 40 positive self-related events, 40 positive other-related events, 40 negative self-related events and 40 negative other-related events. In the self-related events, the participants' real/game names were used to represent the 'self' in the real/game world, respectively. That is, the word ' $\mathrm{I}$ ' or 'me' in the original task was replaced with the participant's real name or game name. The other persons' names in the self-related events were also real names/game names in the real/game world, respectively. In other-related events, the others' real/game names were used to represent the 'other' in the real/game world, respectively.

\section{Procedure}

The total time of this experiment was approximately an hour. Upon arriving at the laboratory, the participants completed a series of self-reported questionnaires, including basic demographic information, the Internet Addiction Test, DSM-V criteria, Self-Esteem Scale [42] and
Beck Depression Inventory (BDI) [43]. Following the task instruction, a shortened sample (ten trials) of the task was conducted outside the scanner to familiarize the participants with the experimental procedure. Afterwards, the participants were asked to complete the formal task inside the scanner.

The formal experiment included two runs - that is, the real-world context and game-world context. At the beginning of each run, the participants were instructed to imagine that the interpersonal events occurred either in the real world or game world and then made causal attributions on a four-point scale. The order of the contexts was counterbalanced between the participants in each group: 12 IGD and 12 RGU participants were randomly assigned to the game-world context first, and the remaining participants completed the real-world context before the game-world context. In each run, 80 trials with 20 trials for each of the four experimental conditions (e.g., self-positive, self-negative, other-positive and other-negative) were pseudorandomized. In terms of self-related trials, 'self' was assigned to the subject position or object position and was the target of evaluation; in terms of other-related trials, the subjects or objects would be the targets of evaluations. The positions of the targets were counterbalanced across trials. The experiment began with a black fixation cross presented on a white screen for $2000 \mathrm{~ms}$, followed by the presentation of stimulus interface displaying one interpersonal event and a 4-point scale (Fig. 1). The participants were required to respond within $6000 \mathrm{~ms}$ for each trial, and after which a red circle would appear around the selected option (lasting for $1000 \mathrm{~ms}$ ). Between trials, an inter-trial interval of $200-3200 \mathrm{~ms}$ (jittered) was used, during which a fixation cross was shown.

\section{Behavioral data analysis}

All behavioral data analyses were conducted using Statistical Package for the Social Sciences version 23.0 (SPSS Inc., Chicago, IL, USA). Considering that individuals may show different levels of self-other bias in causal attribution, the attribution rating difference scores between self and other were initially calculated for each participant, taking the other condition as the baseline [26]. Next, Group (2; IGD, RGU) $\times$ Context $(2$; real world, game world $) \times$ Valence (2; Negative, Positive) repeated-measures analyses of variance (ANOVA) was performed, with Context and Valence as with-in subject variables and Group as the betweensubject variable; the attribution rating difference score (self minus other) was defined as dependent variable, with BDI and self-esteem scores included as covariates. Bonferroni correction was employed for multiple post hoc comparisons. Additionally, independent sample $t$-test and chisquared test were used to compare the demographic data 


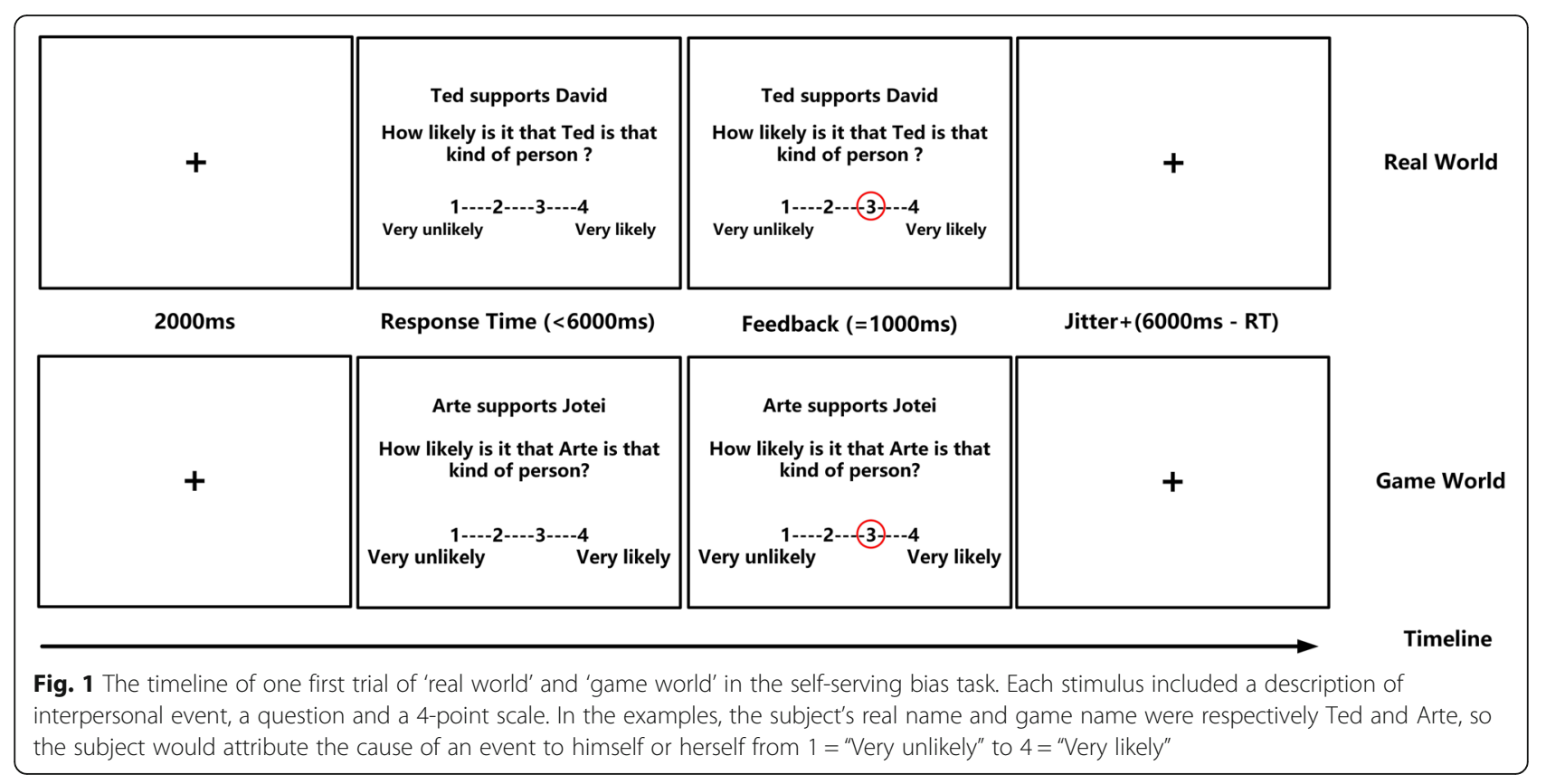

between the groups. All the results with significant effects were reported at the $p<0.05$ level.

Pearson's correlation analyses were conducted for the attribution rating difference scores and questionnaire scores (Self-Esteem Scale and BDI) for RGU and IGD groups, respectively. The correlation results were considered significantly after correction using Sequential Bonferroni correction [44]. Fisher's $Z$-test was applied to compare the correlations between these two groups.

\section{Imaging acquisition and pre-processing}

Brain images were acquired using a Siemens Trio $3 \mathrm{~T}$ scanner at the Functional MRI Laboratory (East China Normal University, Shanghai). An 8-min structural scan was performed before $24 \mathrm{~min}$ of task-related scan for the normalization and coregistration of the functional data. Structural images were collected using a T1-weighted three-dimensional spoiled gradient-recalled sequence (192 slices; slice thickness $=1.0 \mathrm{~mm}$; skip $=0 \mathrm{~mm}$; echo time $\mathrm{TE}=2.98 \mathrm{~ms}$; repetition time $=2530 \mathrm{~ms}$; flip angle $=7^{\circ}$; inversion time $=1100 \mathrm{~ms}$; field of view $=256 \times 256 \mathrm{~mm}$; inplane resolution $=1 \times 1 \mathrm{~mm}$ ) for whole-brain coverage. The functional MRI data were obtained using a gradientecho EPI T2-sensitive pulse sequence in 33 slices (interleaved sequence, $3 \mathrm{~mm}$ thickness; echo time $\mathrm{TE}=30 \mathrm{~ms}$; flip angle $=90^{\circ}$; repetition time $=2000 \mathrm{~ms}$; field of view $=$ $220 \times 220 \mathrm{~mm}$; matrix $64 \times 64$; gap $=0.3 \mathrm{~mm}$ ).

Data preprocessing was conducted using the statistical parametric mapping software package (SPM8, http:// www.fil.ion.ucl.ac.uk/spm/spm8). The first five functional images were discarded due to scanner equilibrium effects. The remaining images were manually reoriented to the anterior-posterior commissure (AC-PC) line, slice-timed, and realigned to the first volume with a mean functional image created. Next, structural images were co-registered to the mean image and spatially normalized to the MNI space, resulting in an isometric voxel size of $2 \times 2 \times 2 \mathrm{~mm}^{3}$ and spatially smoothed using an 8 -mm full-at-half-maximum Gaussian kernel.

\section{Imaging data analysis First-level regression analysis}

In the first-level analysis, two different general linear model (GLM) models were created for each participant. First, a factorial model (GLM1) was applied to confirm the participants' blood oxygen level dependence signal corresponding to each task condition. For both groups, eight conditions were determined according to Context (Real, Game), Valence (Positive, Negative) and Target (Self, Other). The timings of stimulus onset and durations of the response time were convolved with the canonical haemodynamic response function. Second, we also built a parametric model (GLM2) to investigate the brain responses associated with the self-attribution ratings. The rating score was adopted as a parametric regressor to the different weights of the selfrelated positive/negative trials for each context. In both models, the six head-movement parameters were included as regressors of no interest. To improve the signal-to-noise ratio, a high-pass filter (cut-off period $=128 \mathrm{~s}$ ) was applied by filtering out low-frequency noise. Error trials were excluded, and the GLM models were independently applied to each voxel to identify the voxels that were significantly activated. The statistical images created at the individual level were then entered into further analyses. 


\section{Second-level group analysis}

Region of interest (ROI)-based analysis ROI-based analysis was performed to detect group differences between conditions for GLM1. The ROIs were determined based on functional-defined areas that were identified previously as being important for self-serving bias. The regions including the $\operatorname{dmPFC}(\mathrm{x}=12, \mathrm{y}=56, \mathrm{z}=44)$, vmPFC $(\mathrm{x}=12, \mathrm{y}=52, \mathrm{z}=-10)$ and precuneus $\mathrm{pcc}_{\mathrm{pcc}}(\mathrm{ax}=10, \mathrm{y}=-$ $50, z=30)$ described in $[28,45]$ were selected, which also have been used to investigate the processes of selfpositivity bias [45]. All the ROI masks were 10-mm-radius spheres centered at the standard MNI coordinates.

For each ROI, the beta values of the eight conditions were extracted from the statistical images generated from the first-level analysis using the REST toolbox (Version 1.8, https://www.nitrc.org/projects/rest/) and then were subjected to analysis of variance to assess the main effects and interactions. In examining brain activations specific to the self (relative to other) during the process of causal attribution, we calculated the activation difference between self and other and simultaneously tested how the activation difference was modulated by Group, Context and Valence, analogy with behavioral data analyses. Thus, for each ROI, Group (2; IGD, RGU) × Context (2; real world, game world $) \times$ Valence (2; Negative, Positive) repeatedmeasures ANOVAs was conducted, with the difference scores of beta values between self and other defined as the dependent variable. Bonferroni correction was applied when multiple statistical tests were performed simultaneously. Correlation analyses were performed between the difference scores of beta values (self minus other) in specific conditions that demonstrated group differences and attribution rating difference scores.

Parametric analysis For group-level analysis of GLM2, two-sample $t$ tests were conducted based on the subjectspecific estimates of the parametric regressors at each voxel. This allowed us to identify the brain areas that showed differential associations with self-attribution rating scores in the IGD and RGU groups. The results were reported when significant at a voxel-level threshold of $p<0.001$ uncorrected and a cluster-level threshold of $p<0.05$ family wise error (FWE) corrected.

\section{Results}

\section{Behavioral performance}

As the dependent variable, the attribution rating difference scores between self and other (self minus other) in the positive and negative conditions respectively represented the degree of 'self-enhancement' and 'self-protection'. Of note, higher attribution rating difference scores in the positive condition reflected a stronger selfenhancement motivation while higher attribution rating difference scores in the negative condition reflected a weaker self-protection motivation. Repeated-measures ANOVA found no significant main effects of context $[F$ $(1,47)=0.03, p=0.870]$ and group $[F(1,47)=0.50, p=$ $0.48]$ and no significant three-way interaction effect among context, valence and group $[F(1,47)=0.57, p=$ $0.453]$. However, the main effect of valence $[F(1,47)=$ 97.92, $p<0.001$, partial $\left.\eta^{2}=0.69\right]$ and interaction between valence and group $[F(1,47)=17.45, p<0.001$, partial $\left.\eta^{2}=0.28\right]$ reached the significant level. To explore this interaction, simple-effect analysis for group was conducted. As shown in Fig. 2, the IGD participants rated higher in negative events $[F(1,47)=10.56, p=0.002$, partial $\left.\eta^{2}=0.19\right]$ and lower in positive events $[F(1,47)=$ 6.52, $p=0.014$, partial $\eta^{2}=0.13$ ] than the RGU participants, indicating the reductions of both self-protection and self-enhancement in IGD.

Independent $t$-tests showed that the IGD group had higher depression scores [IGD $(M \pm S D)$ : $11.08 \pm 8.12$, RGU $(M \pm S D): 6.76 \pm 5.33, t(47)=2.21, p=0.032, d=0.64]$ and lower self-esteem scores [IGD $(M \pm S D)$ : $27.83 \pm 4.28$, RGU $(M \pm S D): 30.28 \pm 3.61, t(47)=-2.17, p=0.035, d=0.62]$ than the RGU group. We also found negative correlations between the BDI scores and self-esteem scores in these two groups $\left(r_{\mathrm{IGD}}=-0.479, p=0.018 ; r_{\mathrm{RGU}}=-0.461, p=0.020\right.$; Fig. 3a). Fisher's $Z$-test further suggested that the correlations between BDI and self-esteem were not significantly different in these two groups $(-1.96<\mathrm{z}<1.96)$.

Correlation analyses were conducted among the attribution rating difference scores that were averaged across the two contexts, BDI scores and self-esteem scores for each group. Only in the IGD group were the self-esteem scores positively correlated with the attribution rating difference scores in the positive condition $(r=0.513, p=$ 0.010; Fig. 3b). Moreover, the BDI scores were positively

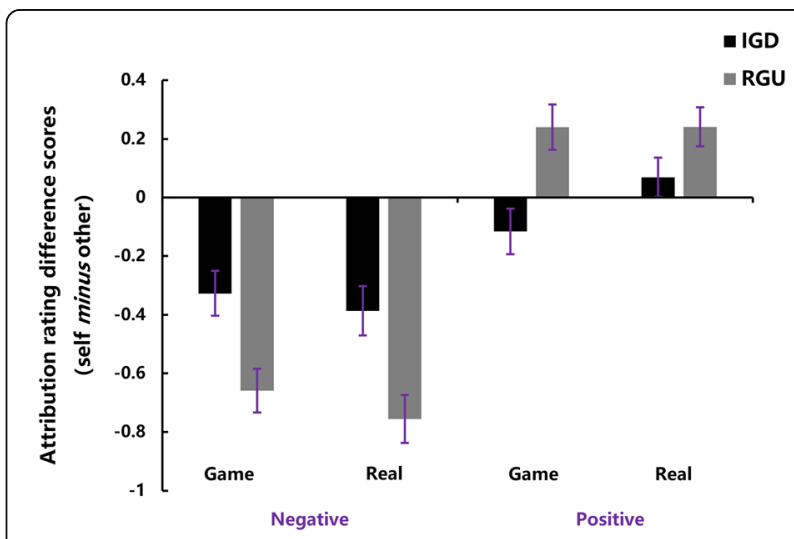

Fig. 2 Behavioral results in IGD and RGU groups: The IGD participants rated higher in the negative condition, but lower in the positive condition than RGU participants, suggesting an attenuated self-serving bias in individuals with IGD (error bars represent standard error of the mean) 


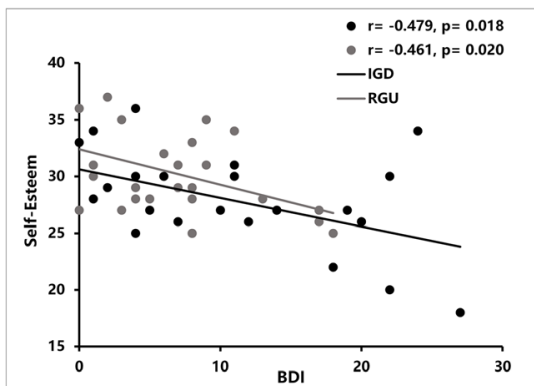

a

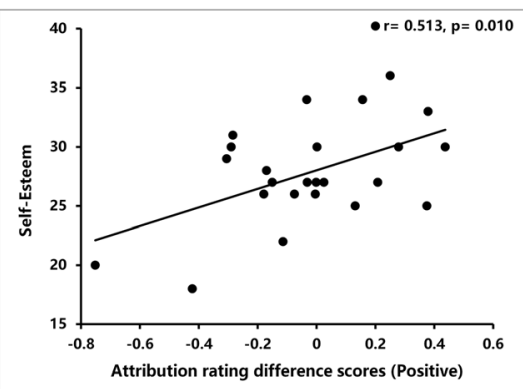

b

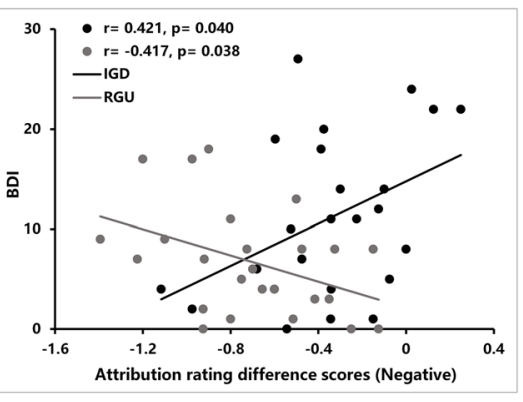

C

Fig. 3 Correlations between behavioral performances and questionnaire scores (Self-Esteem and BDI) within IGD and RGU groups. a Significant negative correlations were observed between BDI scores and self-esteem scores in both IGD and RGU groups; $\mathbf{b}$ Significant positive correlation was observed between self-esteem scores and the attribution rating difference scores in the positive condition in the IGD group, indicating that the IGD participants who with lower self-esteem exhibited lower level of self-enhancement; c Distinct significant correlations were observed between $\mathrm{BDI}$ scores and the attribution rating difference scores in the negative condition in IGD and RGU groups, indicating that the IGD participants who with higher BDI exhibited lower level of self-protection while the RGU participants who with higher the BDI exhibited higher level of self-protection

correlated with the attribution rating difference scores in the negative condition in the IGD group $\left(r_{\text {IGD }}=0.421\right.$, $p=0.040$; Fig. 3c). Within the RGU group, the BDI scores were negatively correlated with the attribution rating difference scores in the negative condition $(r$ RGU $=-$ $0.417, p=0.038$; Fig. 3c).

\section{Imaging results \\ ROI analysis}

The results of ANOVA with repeated measures showed a two-way significant interaction effect between group and valence in the vmPFC $[F(1,47)=4.81, p=0.033$, partial $\left.\eta^{2}=0.09\right]$. Subsequent simple-effect analysis performed on the groups showed that the IGD group exhibited increased brain response in the vmPFC than the RGU group in the negative condition $[F(1,47)=4.42, p=0.041$, partial $\eta^{2}=0.09$ ], but no group difference was found in the positive condition $[F(1,47)=0.55, p=0.461]$ (Fig. 4a). Additionally, in the negative condition, the mean beta values of the vmPFC (self minus other) across two contexts were positively correlated with the mean attribution rating difference scores across two contexts in the IGD group, indicating that higher vmPFC activation predicted a lower level of self-protection $(r=0.485, p=0.016$; Fig. $4 b)$. No other main effects or interactions were significant for the ROI of the vmPFC.

For the ROI of the precuneus $\mathrm{pcc}_{\mathrm{pc}}$, we found a significant three-way interaction among group, context and valence $\left[F(1,47)=5.19, p=0.027\right.$, partial $\left.\eta^{2}=0.10\right]$. Simple-effect analysis showed a significant group $\times$ context interaction in the positive condition $[F(1,47)=4.09, p=0.049$, partial $\left.\eta^{2}=0.08\right]$ but not in the negative condition $[F(1,47)=$ $0.69, p=0.411]$. Further analysis showed that, in the positive condition, the IGD group exhibited lower precuneus $_{\text {pcc }}$ activation in the real world than the RGU group
[Beta values: IGD $(M \pm S E)$ : $0.26 \pm 0.10$, RGU $(M \pm S E)$ : $0.63 \pm 0.10, F(1,47)=6.51, p=0.014$, partial $\eta^{2}=0.12$ ], but no significant group difference was observed in the game world [Beta values: IGD $(M \pm S E): 0.29 \pm 0.12$, RGU $(M \pm S E): 0.11 \pm 0.12, F(1,47)=1.16, p=0.29]$ (Fig. 5).

For the ROI of the dmPFC, no main effect was found regarding group $[F(1,47)=0.35, p=0.56]$ or interaction with group [group $\times$ context: $F(1,47)=0.69, p=0.41$; group $\times$ valence: $F(1,47)=0.03, p=0.87$; group $\times$ context $\times$ Valence: $F(1,47)=0.76, p=0.39$ ].

\section{Parametric analysis}

In the positive condition, positive correlations between the attribution rating scores of self-related events and activations in the regions of the precuneus, inferior frontal gyrus and middle temporal gyrus were reduced in the IGD group relative to the RGU group in the realworld context. However, in the negative condition, negative correlations between the attribution rating scores of self-related events and activation in the regions of the inferior parietal lobule, superior frontal gyrus and precentral gyrus were enhanced in the IGD group compared with those in the RGU group in the game-world context (Table 2). No other significant difference was observed between the groups.

\section{Discussion}

To our best knowledge, this is the first study to clarify the behavioral and neural correlates of self-serving bias in individuals with IGD and RGU. A modified selfserving bias task was adopted to examine how they made causal attributions in game-world and real-world contexts. At the behavioral level, the individuals with IGD exhibited an attenuated self-serving bias with relatively diminished self-protection and self-enhancement, a 


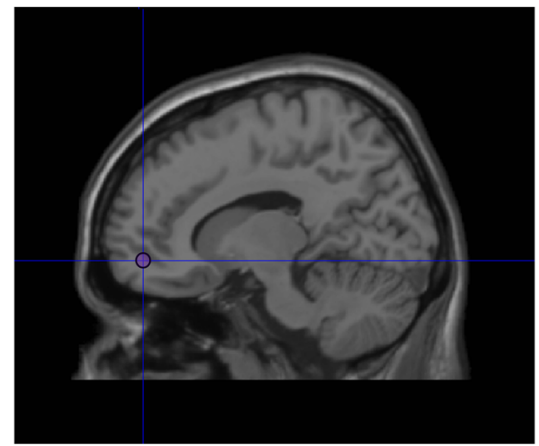

$\operatorname{vmPFC}(x=12, y=52, z=-10)$

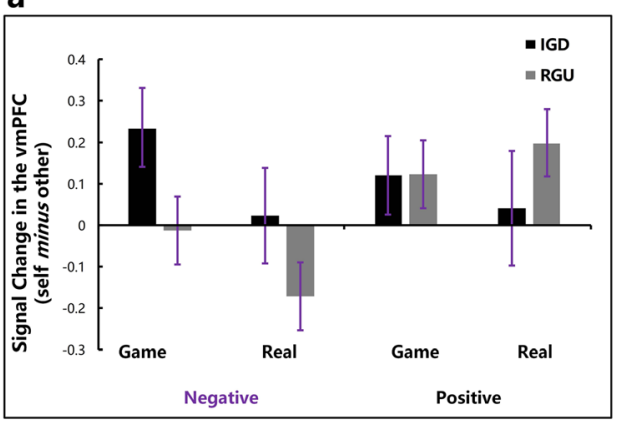

b

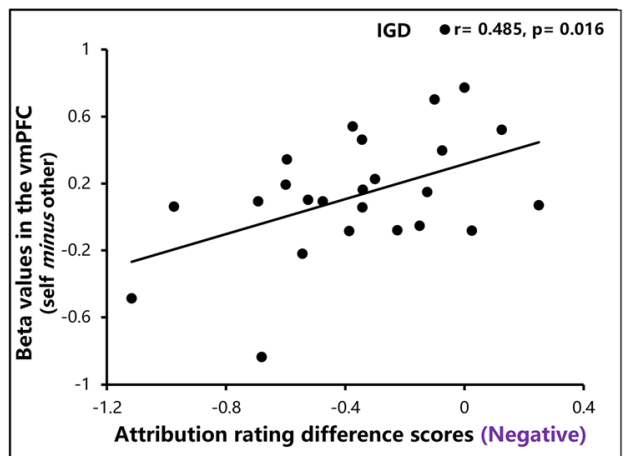

Fig. 4 In the negative condition, increased VmPFC activation in the IGD group was associated with lower level of self-protection. a The IGD group exhibited increased VMPFC activation during attributions of negative events in both contexts compared with RGU group (error bars represent standard error of the mean); $\mathbf{b}$ Significant positive correlation was observed between the attribution rating difference scores and beta values of the VMPFC (self minus other) in the negative condition in the IGD group, indicating that the IGD participants who with lower level of self-protection motivation exhibited higher vmPFC activation

finding that was consistent with our hypotheses. At the neural level, the IGD group demonstrated increased vmPFC activation during attributing negative events compared with the RGU group in both contexts, and the individuals with IGD with higher vmPFC activation showed a lower level of self-protection. However, in the IGD group relative to the RGU group, decreased precuneus $_{\text {pcc }}$ activation was found during attributing positive events in the real world, and the positive correlation between precuneus activation and the attribution rating scores of self-related positive events was reduced.

In the development process of human life, individuals spontaneously strive to understand the world through attributing the cause of events and usually build an adaptive attributional pattern of self-serving bias [46]. The RGU group, as the controls, are inclined to connect valenced events with 'plausible' causes to foster a positive self-concept. However, a depressive pattern of self-

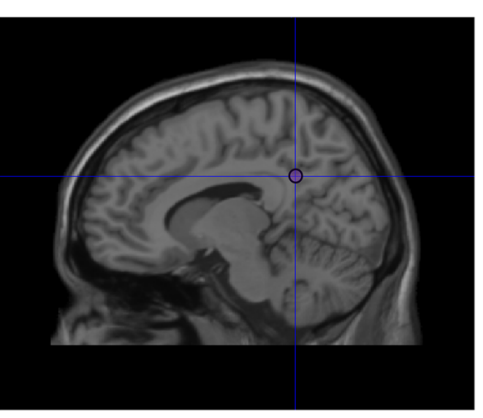

Precuneus $(x=10, y=-50, z=30)$

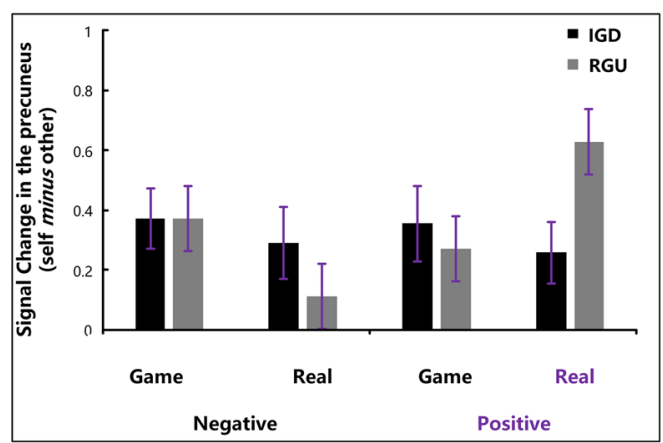

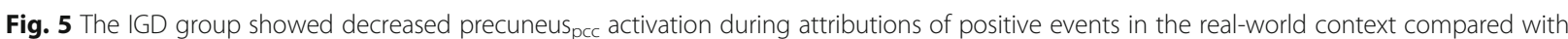
RGU group (error bars represent standard error of the mean) 
Table 2 Group differences for the parametric contrasts in different conditions (IGD $>$ RGU, voxel-level $p<0.001$ uncorrected and cluster-level FWE $p<0.05$ corrected)

\begin{tabular}{|c|c|c|c|c|}
\hline Region $^{a}$ & $\mathrm{H}$ & $x, y, z^{b}$ & Max $t$ & Number of voxels \\
\hline \multicolumn{5}{|l|}{ Negative_Game world } \\
\hline \multicolumn{5}{|c|}{ Decrease with higher rating scores } \\
\hline Inferior parietal lobule & L & $-46,-54,56$ & 3.90 & 272 \\
\hline Superior frontal gyrus & $\mathrm{R}$ & $22,22,50$ & 4.11 & 276 \\
\hline Precentral gyrus & $\mathrm{R}$ & $24,-22,70$ & 4.41 & 562 \\
\hline \multicolumn{5}{|l|}{ Positive_Real World } \\
\hline \multicolumn{5}{|c|}{ Decrease with lower rating scores } \\
\hline Precuneus & L & $-20,-54,54$ & 4.42 & 290 \\
\hline Inferior frontal gyrus & L & $-38,32,6$ & 5.03 & 364 \\
\hline Middle temporal gyrus & L & $-56,-58,12$ & 4.40 & 467 \\
\hline
\end{tabular}

${ }^{\text {a }}$ The brain regions with maximal $t$ score were selected to be shown

b Peak Montreal Neurological Institute (MNI) coordinates

serving bias was observed in the IGD group. They made excessively internal attributions for negative events and external attributions for positive events, indicating the deficits in both self-protection and self-enhancement. Consistent with these findings, prior research has reported that individuals with IGD are likely to be thwarted in attaining identity formation and are vulnerable to negative feedback, which might substantiate the inabilities to find ways to discount such feedback and protect the self from threats [47, 48]. Another study asked participants to rate how well the adjectives described themselves and discovered that the individuals with IGD rated themselves less positively than healthy controls, suggesting a lower level of motivation to maintain a favorable self-view in IGD [21]. Moreover, especially during dealing with attributions of interpersonal events, the individuals with IGD evaluated themselves as having more negative traits and fewer positive traits, which might potentially exert a negative impact on interpersonal attitude formation [49]. To some extent, it may further clarify why people with IGD cannot maintain good family and interpersonal relationships.

Additionally, the RGU group reported high self-esteem and low depression, and those with relatively higher BDI score exhibited a higher motivation of self-protection. These findings may suggest that the RGUs adopted various self-protective tactics to resist depressive symptoms and preserve positive self-view, further indicating that they could adaptively regulate self-protective behavior. Unlike the RGU group, the IGD group reported low self-esteem and high depression. The behavioral results in our study also demonstrated that people with low self-esteem and high depression showed less self-serving bias, a finding that agrees with previous work [24, 25]. More interestingly, within the IGD group, lower self-esteem was associated with a lower level of self-enhancement while a higher BDI score was associated with a lower level of self-protection. It could be speculated that the individuals with IGD were less motivated to achieve gains for their self-esteem and easily perturbed by dysthymia without effectively protecting themselves from depressed mood. What's more, these correlational findings suggested intriguing possibilities that self-esteem and depression have predictive abilities regarding self-enhancement and self-protection, respectively. Correlation analysis also revealed an inverse relationship between depression and self-esteem in both groups, reflecting that individuals with low self-esteem were susceptible to depression [50]. Hence, it is important to develop interventions that enhance self-esteem and reduce depression, especially for individuals with IGD.

Neurobiologically, the individuals with IGD showed increased brain activation in the vmPFC when assigning internal causes of negative valenced events. It is widely acknowledged that the vmPFC is commonly activated when individuals process self-relevant information [51, 52]. More specifically, this region also plays a vital role in appraising and representing the personal value or significance of self-related contents during self-processing [53, 54]. Thus, the increased vmPFC activation observed in the IGD group may imply additional endeavor to evaluate the extent to which they viewed negative events as caused by themselves. However, the decreased motivation of selfprotection the individuals with IGD exhibited, the increased cognitive endeavor they employed to evaluate negative valenced events. A possible interpretation for this phenomenon was that the gaming addicts could not protect their self-concept from negative information, indicating a deficit in self-protective function in IGD. In addition, many studies have demonstrated that individuals with low self-esteem are particularly sensitive to negatively valenced information and devote more attentional resources to negative stimuli $[55,56]$. With this in mind, our current findings may also suggest that the individuals with IGD were oversensitive to negative self-related information and 
could not avoid negative self-evaluation, providing further evidence for the impaired self-protective ability in IGD.

Moreover, during attributing positive events, the IGD group exhibited decreased precuneus $\mathrm{pcc}_{\mathrm{pc}}$ activation compared with the RGU group in the real world. The precuneus $_{\mathrm{pcc}}$ has been proven to be involved in self-referential processing and causal attribution [31, 57]. For example, the precuneus $\mathrm{p}_{\mathrm{pcc}}$ is engaged during tasks that require specific judgements of self-relevant traits compared with selfirrelevant traits or that attribute causes of social positive or negative events. More precisely, it is clearly evidenced

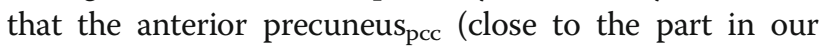
study) is implicated in internal attribution during the evaluation of positively valenced situations [34]. What's more, another study reported that individual variations in subjective core value ratings were tracked by the precuneus $_{\mathrm{pcc}}$, indicating the extent to which a value was perceived as an internalized part of a person's self-concept [58]. Therefore, the lower precuneus pcc $_{\text {activation in facing }}$ positive events may be explained by the intrinsic characteristic of assigning less positive subjective value to selfrelated information on which the individuals with IGD based their actions (less internal attributions for positive events). Furthermore, we found a reduced positive correlation between activation in the precuneus $\mathrm{pcc}_{\mathrm{pcc}}$ and attribution ratings of positive events in the IGD group in the real world, revealing that individuals with IGD tended to view themselves in less positive terms and lowered their standing on positive traits.

Overall, the attenuated self-serving bias in IGD was pertinent to the aberrant functioning of CMS regions critically implicated in self-related processing. Considering the negative attitude towards self-concept for individuals with IGD, future studies should adopt strategies to improve and protect their self-esteem and maintain a positive self-concept. Early studies have detected that self-affirmation interventions can bring about an expansive view of the self and sustain the self-integrity, lead to great intentions to reduce alcohol consumption and the number of cigarettes smoked and result in lasting benefits in education, health and relationships [59-61]. Thus, self-affirmation may to some extent help individuals with IGD build a positive self-view, relieve symptoms of craving and withdrawal and promote academic achievement. Additionally, future studies should use other brainimaging technologies to replicate the study with a larger sample size. As a non-invasive, portable and costeffective neuroimaging technique, functional nearinfrared spectroscopy (fNIRS) could evaluate cerebral haemodynamic variations of specific ROIs during cognitive tasks and distinguish patient populations from healthy individuals with acceptable sensitivity, which provided an efficient way to probe into the self-serving bias involving large samples of IGD [62, 63].

\section{Conclusion}

In this study, we examined the behavioral and neural correlates of self-serving bias in individuals with IGD and RGUs, further extending our understanding of the self-related cognition of IGD. The individuals with IGD showed an attenuated self-serving bias with reductions in both self-enhancement and self-protection and exhibited altered brain activations within the CMS regions including the vmPFC and precuneus pcc $_{\text {. These results may }}$ indicate the intrinsic negative self-view and impaired adaptive functions in defending against negative selfconcept and elevating positive self-concept in IGD. Clinical treatments from the insights of improving selfesteem and building a positive self-view may be potent for intervention and treatment of IGD.

\section{Abbreviations}

IGD: Internet Gaming Disorder; RGU: Recreational Internet Gaming User; CMS: Cortical Midline Structures; vmPFC: ventromedial Prefrontal Cortex; dmPFC: dorsomedial Prefrontal Cortex; ROI: region of interest; IAT: Internet Addiction Test; BDI: Beck Depression Inventory; DSM-V: Diagnostic and Statistical Manual of Mental Disorders Fifth Edition; ICD-11: the 11th Revision of the International Classification of Diseases; fNIRS: functional near-infrared spectroscopy

\section{Acknowledgments}

This research was supported by the Major project of medicine science and technology of PLA (Grant no. AWS17J012); and Shanghai Leading talent Plan. We also would like to express our sincere gratitude to the editor and anonymous reviewers for their valuable comments, which have greatly improved this article.

\section{Authors' contributions}

YW, CW and XG devised the concept and supervised the study. YW contributed to fMRI data collection, analyzed the data and wrote the first draft of the manuscript. YW, LZ, and CW contributed to the interpretation of data. $L Z, C W$ and $X G$ revised and improved the manuscript. All authors have approved the final manuscript.

\section{Funding}

This research was supported by the Major project of medicine science and technology of PLA (Grant no. AWS17J012); and Shanghai Leading talent Plan. The funders had no impact in study design, data collection, data analyses and interpretation, as well as the preparation and submission of the manuscript.

\section{Availability of data and materials}

The datasets used and/or analyzed during the current study are available from the corresponding author on reasonable request.

\section{Ethics approval and consent to participate}

The present research was approved by the Human Research Ethics Committee of East China Normal University (reference number: HR013-2018). Written consent was obtained from all participants before the start of the study.

\section{Consent for publication}

Not applicable.

\section{Competing interests}

The authors declared that there were no competing interests exist.

\section{Author details}

${ }^{1}$ School of Psychology and Cognitive Science, East China Normal University, No. 3663, North Zhongshan Road, Shanghai 200062, China. ${ }^{2}$ Shanghai Key Laboratory of Magnetic Resonance, Department of Physics, East China Normal University, No. 3663, North Zhongshan Road, Shanghai 200062, 
China. ${ }^{3}$ National Demonstration Center for Experimental Psychology Education, East China Normal University, No. 3663, North Zhongshan Road, Shanghai 200062, China.

\section{Received: 16 July 2020 Accepted: 11 October 2020}

Published online: 20 October 2020

\section{References}

1. Meng Y, Deng W, Wang H, Guo W, Li T. The prefrontal dysfunction in individuals with internet gaming disorder: a meta-analysis of functional magnetic resonance imaging studies. Addict Biol. 2015;20(4):799-808. https://doi.org/10.1111/adb.12154.

2. Petry NM, Rehbein F, Gentile DA, Lemmens JS, Rumpf HJ, Mãqũ̈̈Le T, et al. An international consensus for assessing internet gaming disorder using the new DSM-5 approach. Addiction. 2014;109(9):1399-406.doi: https://doi.org/ 10.1111/add.12457.

3. Mak K-K, Lai C-M, Ko C-H, Chou C, Kim D-I, Watanabe H, et al. Psychometric properties of the revised Chen internet addiction scale (CIAS-R) in Chinese adolescents. J Abnorm Child Psychol. 2014;42(7):1237-45. https://doi.org/10. 1007/s10802-014-9851-3

4. Lai CM, Kwok-Kei M, Hiroko W, Ang RP, Pang JS, Ho RCM. Psychometric properties of the internet addiction test in Chinese adolescents. J Pediatr Psychol. 2013;7:794-807. https://doi.org/10.1093/jpepsy/jst022.

5. Tran BX, Mai HT, Nguyen LH, Nguyen CT, Latkin CA, Zhang MWB, et al. Vietnamese validation of the short version of internet addiction test. Addict Behav Rep. 2017:6:45-50. https://doi.org/10.1016/j.abrep.2017.07.001.

6. Kim EJ, Namkoong K, Ku T, Kim SJ. The relationship between online game addiction and aggression, self-control and narcissistic personality traits, European Psychiatry. 2008;23(3):212-8. https://doi.org/10.1016/j.eurpsy.2007. 10.010.

7. Kuss DJ, Griffiths MD. Internet gaming addiction: a systematic review of empirical research. Int J Mental Health Addiction. 2012;10(2):278-96. https:// doi.org/10.1007/s11469-011-9318-5.

8. Ho RC, Zhang MW, Tsang TY, Toh AH, Pan... F. The association between internet addiction and psychiatric co-morbidity: a meta-analysis. Bmc Psychiatry. 2014;14(1):183.doi:https://doi.org/10.1186/1471-244X-14-183.

9. American Psychiatric Association. Diagnostic and Statistical Manual of Mental Disorders (DSM-5 ${ }^{\oplus}$ ). Washington DC: American Psychiatric Pub; 2013.

10. Reed GM, First MB, Kogan CS, Hyman SE, Saxena S. Innovations and changes in the ICD-11 classification of mental, behavioural and neurodevelopmental disorders. World Psychiatry. 2019;18(1):3-19. https:// doi.org/10.1002/wps.20611.

11. Schiebener J, Brand M. Decision-making and related processes in internet gaming disorder and other types of internet-use disorders. Current Addiction Reports. 2017;4(3):1-10. https://doi.org/10.1007/s40429-017-0156-9.

12. Dong GH, Potenza MN. A cognitive-behavioral model of internet gaming disorder: theoretical underpinnings and clinical implications. J Psychiatr Res. 2014:58:7-11. https://doi.org/10.1016/J.Jpsychires.2014.07.005.

13. Wang $Y$, Wu L, Zhou H, Lin X, Zhang Y, Du X, et al. Impaired executive control and reward circuit in internet gaming addicts under a delay discounting task: independent component analysis. Eur Arch Psychiatry Clin Neurosci. 2017; 267(3):245-55. Epub 2016/08/11. https://doi.org/10.1007/s00406-016-0721-6.

14. Zacarias M, Caetano A, Magalhães R, Pinto HS, Tribolet J. Towards Organizational Self-Awareness: An Initial Architecture and Ontology. In: Rittgen P, editor. Ontologies for Business Interactions: IDEA Group; 2008. p. 101-121.

15. Sedikides C, Strube MJ. The multiply motivated self. Personal Soc Psychol Bull. 1995;21(12):1330-5. https://doi.org/10.1177/01461672952112010.

16. Snyder M, Uranowitz SW. Reconstructing the past: some cognitive consequences of person perception. J Pers Soc Psychol. 1978;36(9):941-50. https://doi.org/10.1037/0022-3514.36.9.941

17. Miller DT, Ross M. Self-serving biases in the attribution of causality: fact or fiction? Psychol Bull. 1975;82(2):213-25. https://doi.org/10.1037/h0076486.

18. Hewstone M. Causal attribution: from cognitive processes to collective beliefs. Oxford: Basil Blackwell; 1989.

19. Blaine B, Crocker J. Self-esteem and self-serving biases in reactions to positive and negative events: An integrative review. Self-esteem: Springer; 1993. p. 55-85.

20. Mezulis AH, Abramson LY, Hyde JS, Hankin BL. Is there a universal positivity bias in attributions? A meta-analytic review of individual, developmental, and cultural differences in the self-serving attributional bias. Psychol Bull. 2004;130(5):711-47. https://doi.org/10.1037/0033-2909.130.5.711.
21. Kim M-K, Jung YH, Kyeong S, Shin Y-B, Kim E, Kim J-J. Neural correlates of distorted self-concept in individuals with internet gaming disorder: a functional MRI study. Front Psychiatry. 2018;9:330. https://doi.org/10.3389/ fpsyt.2018.00330.

22. Ko CH, Yen J-Y, Chen C-C, Chen S-H, Yen C-F. Gender differences and related factors affecting online gaming addiction among Taiwanese adolescents. J Nerv Ment Dis. 2005;193(4):273-7. https://doi.org/10.1097/01. nmd.0000158373.85150.57

23. Burleigh TL, Stavropoulos V, Liew LWL, Adams BLM, Griffiths MD. Depression, internet gaming disorder, and the moderating effect of the gamer-avatar relationship: an exploratory longitudinal study. Int J Mental Health Addiction. 2018;16:102-24. https://doi.org/10.1007/s11469-017-9806-3.

24. Campbell WK, Sedikides C. Self-threat magnifies the self-serving bias: a meta-analytic integration. Rev Gen Psychol. 1999;3(1):23-43. https://doi.org/ 10.1037/1089-2680.3.1.23.

25. Taylor SE, Brown JD. Illusion and well-being: a social psychological perspective on mental health. Psychol Bull. 1988;103(2):193-210. https://doi. org/10.1037/0033-2909.103.2.193

26. Wang $X$, Zheng L, Li L, Zheng $Y$, Sun $P$, Zhou FA, et al. Immune to Situation: The Self-Serving Bias in Unambiguous Contexts. Front Psychol. 2017;8:882. https://doi.org/10.3389/fpsyg.2017.00822.

27. Northoff G, Bermpohl F. Cortical midline structures and the self. Trends Cogn Sci. 2004;8(3):102-7. https://doi.org/10.1016/j.tics.2004.01.004.

28. Rameson LT, Satpute AB, Lieberman MD. The neural correlates of implicit and explicit self-relevant processing. Neuroimage. 2010;50(2):701-8. https:// doi.org/10.1016/j.neuroimage.2009.12.098.

29. Moran JM, Heatherton TF, Kelley WM. Modulation of cortical midline structures by implicit and explicit self-relevance evaluation. Soc Neurosci. 2009:4(3):197-211. https://doi.org/10.1080/17470910802250519.

30. Blackwood N, Bentall R, Simmons A, Murray R, Howard R. Self-responsibility and the self-serving bias: an $\mathrm{fMRI}$ investigation of causal attributions. Neurolmage. 2003;20(2):1076-85. https://doi.org/10.1016/s1053-8119(03)00331-8.

31. Seidel E-M, Eickhoff SB, Kellermann T, Schneider F, Gur RC, Habel U, et al. Who is to blame? Neural correlates of causal attribution in social situations. Soc Neurosci. 2010;5(4):335-50. https://doi.org/10.1080/17470911003615997.

32. Beer JS, Hughes BL. Neural systems of social comparison and the "aboveaverage" effect. Neurolmage. 2010;49(3):2671-9. https://doi.org/10.1016/j. neuroimage.2009.10.075.

33. Yoon L, Somerville LH, Kim H. Development of MPFC function mediates shifts in self-protective behavior provoked by social feedback. Nat Commun. 2018;9(1):3086. https://doi.org/10.1038/s41467-018-05553-2.

34. Cabanis M, Pyka M, Mehl S, Muller BW, Loosjankowiak S, Winterer G, et al. The precuneus and the insula in self-attributional processes. Cognitive Affective Behavioral Neuroscience. 2013;13(2):330-45. https://doi.org/10 3758/s13415-012-0143-5.

35. Wang H, Jin C, Kai Y, Mehmood ST, Mao C, Xuan N, et al. The alteration of gray matter volume and cognitive control in adolescents with internet gaming disorder. Front Behavioral Neuroence. 2015;9:64. https:/doi.org/10.3389/fnbeh.2015.00064.

36. Kuss DJ, Pontes HM, Griffiths MD. Neurobiological correlates in internet gaming disorder: a systematic literature review. Front Psychiatry. 2018;9:166. https://doi.org/10.3389/fpsyt.2018.00166.

37. Yao Y-W, Liu L, Ma S-S, Shi X-H, Zhou N, Zhang J-T, et al. Functional and structural neural alterations in internet gaming disorder: a systematic review and meta-analysis. Neurosci Biobehav Rev. 2017;83:313-24. https://doi.org/ 10.1016/j.neubiorev.2017.10.029.

38. Wang Y, Wu L, Wang L, Zhang Y, Du X, Dong G. Impaired decision-making and impulse control in internet gaming addicts: evidence from the comparison with recreational internet game users. Addict Biol. 2017;22(6): 1610-21. Epub 2016/10/01. https://doi.org/10.1111/adb.12458.

39. Dong G, Li H, Wang L, Potenza M. Cognitive control and reward/loss processing in internet gaming disorder: results from a comparison with recreational internet game-users. Eur Psychiatry. 2017;44:30-8. https://doi. org/10.1016/j.eurpsy.2017.03.004.

40. Zhang J, Dong $H$, Zhao Z, Chen S, Jiang Q, Du X, et al. Altered Neural Processing of Negative Stimuli in People with Internet Gaming Disorder: fMRI Evidence from the Comparison with Recreational Game Users. J Affective Disorders. 2020;In press.doi:https://doi.org/10.1016/j.jad.2020.01.008.

41. Young. Internet Addiction Test (IAT). From http://netaddictioncom/ indexphp?option=combfquiz\&view=onepage\&catid=46\&ltemid=106. 2009.

42. Rosenberg M. Society and the adolescent self-image. Princeton: Princeton University Press; 1965. 
43. Beck AT, Ward CH, Mendelson M, Mock J, Erbaugh J. An inventory for measuring depression. Archives General Psychiatry. 1961;4:561-71. https:// doi.org/10.1001/archpsyc.1961.01710120031004.

44. Holm S. A Simple Sequentially Rejective Multiple Test Procedure. Scand J Stat. 1979;6(2):65-70. https://doi.org/10.2307/4615733.

45. Yang J, Dedovic K, Guan L, Chen Y, Qi M. Self-esteem modulates dorsal medial prefrontal cortical response to self-positivity bias in implicit selfrelevant processing. Soc Cognitive Affective Neurosci. 2014;9(11):1814-8. https://doi.org/10.1093/scan/nst181.

46. Wong PT, Weiner B. When people ask \"why" questions, and the heuristics of attributional search. J Pers Soc Psychol. 1981;40(4):650-63. https://doi.org/ 10.1037/0022-3514.40.4.650.

47. Kim K, Ryu E, Chon M-Y, Yeun E-J, Choi S-Y, Seo J-S, et al. Internet addiction in Korean adolescents and its relation to depression and suicidal ideation: a questionnaire survey. Int J Nurs Stud. 2006;43(2):185-92. https://doi.org/10. 1016/j.jijnurstu.2005.02.005.

48. Yao Y-W, Chen P-R, Chen C, Wang L-J, Zhang J-T, Xue G, et al. Failure to utilize feedback causes decision-making deficits among excessive internet gamers. Psychiatry Res. 2014;219(3):583-8. https://doi.org/10.1016/j.psychres.2014.06.033.

49. Walther E, Trasselli C. I like her, because I like myself: self-evaluation as a source of interpersonal attitudes. Exp Psychol. 2003;50(4):239-46. https://doi. org/10.1026//1618-3169.50.4.239.

50. Orth U, Robins RW. Understanding the link between low self-esteem and depression. Curr Dir Psychol Sci. 2013;22(6):455-60. https://doi.org/10.1177/ 0963721413492763.

51. Kim K, Johnson MK. Extended self: spontaneous activation of medial prefrontal cortex by objects that are 'mine'. Soc Cogn Affect Neurosci. 2014; 9(7):1006-12. https://doi.org/10.1093/scan/nst082.

52. D'Argembeau A, Salmon E. The neural basis of semantic and episodic forms of self-knowledge: insights from functional neuroimaging. Adv Exp Med Biol. 2012;739:276-90. https://doi.org/10.1007/978-1-4614-1704-0_18.

53. D'Argembeau A. On the role of the ventromedial prefrontal cortex in selfprocessing: the valuation hypothesis. Front Hum Neurosci. 2013;7(7):372. https://doi.org/10.3389/fnhum.2013.00372.

54. Kim K, Johnson MK. Activity in ventromedial prefrontal cortex during selfrelated processing: positive subjective value or personal significance? Soc Cogn Affect Neurosci. 2015;10:494-500. https://doi.org/10.1093/scan/nsu078.

55. Richter A, Ridout N. Self-esteem moderates affective reactions to briefly presented emotional faces. J Res Pers. 2011;45(3):328-31. https://doi.org/10. 1016/j.jp.2011.02.008.

56. Dandeneau SD, Baldwin MW. The buffering effects of rejection-inhibiting attentional training on social and performance threat among adult students. Contemp Educ Psychol. 2009;34:42-50. https://doi.org/10.1016/j.cedpsych.2008.05.004.

57. Cavanna AE, Trimble MR. The precuneus: a review of its functional anatomy and behavioural correlates. Brain. 2006;129(3):564-83. https://doi.org/10. 1093/brain/awl004

58. Brosch T, Coppin G, Schwartz S, Sander D. The importance of actions and the worth of an object: dissociable neural systems representing core value and economic value. Soc Cogn Affect Neurosci. 2012;7(5):497-505. https:// doi.org/10.1093/scan/nsr036

59. Cohen GL, Sherman DK. The psychology of change: self-affirmation and social psychological intervention. Annu Rev Psychol. 2014;65(1):333-71. https://doi.org/10.1146/annurev-psych-010213-115137.

60. Harris PR, Napper L. Self-affirmation and the biased processing of threatening health-risk information. Personality Soc Psychol Bull. 2005;31(9): 1250-63. https://doi.org/10.1177/0146167205274694.

61. Armitage CJ, Harris PR, Hepton G, Napper L. Self-affirmation increases acceptance of health-risk information among UK adult smokers with low socioeconomic status. Psychol Addictive Behaviors J Soc. 2008;22(1):88-95. https://doi.org/10.1037/0893-164X.22.1.88.

62. Ho CSH, Lim LJH, Lim AQ, Chan NHC, Tan RS, Lee SH, et al. Diagnostic and Predictive Applications of Functional Near-Infrared Spectroscopy for Major Depressive Disorder: A Systematic Review. Front Psychiatry. 2020;1(378).doi: https://doi.org/10.3389/fpsyt.2020.00378.

63. Husain SF, Yu R, Tang TB, Tam WW, Ho RC. Validating a functional near-infrared spectroscopy diagnostic paradigm for major depressive disorder. Scentific Reports. 2020;10(1):9740. https://doi.org/10.1038/s41598-020-66784-2.

\section{Publisher's Note}

Springer Nature remains neutral with regard to jurisdictional claims in published maps and institutional affiliations.

Ready to submit your research? Choose BMC and benefit from:

- fast, convenient online submission

- thorough peer review by experienced researchers in your field

- rapid publication on acceptance

- support for research data, including large and complex data types

- gold Open Access which fosters wider collaboration and increased citations

- maximum visibility for your research: over $100 \mathrm{M}$ website views per year

At BMC, research is always in progress.

Learn more biomedcentral.com/submissions 